\title{
"La revolución de los españoles en Aranjuez": el mito del 19 de marzo hasta la Constitución de Cádiz
}

\author{
Antonio Calvo Maturana \\ Universidad de Alicante \\ antonio.calvo@ua.es
}

Fecha de recepción: 15/12/2011

Fecha de aceptación: 10/09/2012

\section{RESUMEN}

Como todo nacionalismo, el español ha sido forjado con mitos y contramitos. El Motín de Aranjuez, episodio histórico que hoy conocemos como una intriga cortesana, no tuvo esa imagen en los años posteriores a 1808. Este artículo hará un seguimiento de los numerosos autores y políticos que consideraron el 19 de marzo como el inicio de la revolución en España. Esta efeméride tuvo tanto peso, que la Constitución de 1812 fue proclamada en su aniversario. Con esta coincidencia, los diputados de Cádiz no sólo homenajeaban a Fernando VII, también situaban a Godoy como símbolo de la tiranía. Según vayamos conociendo la evolución de este mito de corto recorrido y los motivos tanto de su adopción como de su abandono, buscaremos el contrapunto del Dos de Mayo, una fecha que siguió siendo conmemorada más allá de 1814 y que ha sido recientemente revitalizada con motivo de su segundo centenario.

Palabras clave: Fernando VII, Manuel Godoy, Motín de Aranjuez, Dos de Mayo, Cortes de Cádiz, Constitución de 1812, Nacionalismo Español.

\section{"The Spaniard's Revolution at Aranjuez": the $19^{\text {th }}$ of March Myth up to the Enactment of the Cadiz Constitution}

\begin{abstract}
As all the nationalisms, the Spanish one is built through myths and anti-myths. The Mutiny of Aranjuez, currently known as a courtier intrigue, didn't carry the same image in the following years after 1808 . This essay will study many authors and politicians who considered the $19^{\text {th }}$ of March as the beginning of the Spanish Revolution. This anniversary was so important that its date was the one chosen to proclaim the Constitution of 1812 four years later. With this coincidence, the deputies of the Cadiz Courts did not just pay tribute to Fernando VII, but also marked Godoy as a symbol of despotism. At the same time, we will compare this ephemeral myth with the Dos de Mayo Uprising, still commemorated and recently revitalized because of its bicentennial.
\end{abstract}

Key words: Fernando VII, Manuel Godoy, Mutiny of Aranjuez, Dos de Mayo Uprising, Cádiz Cortes, Spanish Constitution of 1812, Spanish Nationalism. 
El estudio de la mitificación de un episodio histórico puede ser tan interesante o más que el acontecimiento en sí. Es fundamental saber por qué nacen y en qué condiciones -y gracias a qué intereses- se desarrollan o mueren diferentes concepciones de un mismo hecho. Se puede decir que la identificación y el análisis de estas imágenes no sólo son útiles para la Historia Cultural, sino para un conocimiento positivo de la realidad histórica en cuestión, ya que nuestra aspiración es verla libre -si es que esto es posible- de su metamorfosis histórica e historiográfica.

Precisamente, los seis años que en España conocemos como Guerra de la Independencia (1808-1814) están llenos de momentos y personajes cuya interpretación sigue dando lugar al debate historiográfico dos siglos más tarde ${ }^{1}$. Nos vamos a centrar aquí en los inicios de este sexenio para estudiar cómo percibieron el Motín de Aranjuez los españoles contemporáneos a aquella revuelta que -entre el 17 y el 19 de marzo de 1808- provocó la caída de Manuel Godoy y la abdicación de su protector Carlos IV.

En las próximas páginas veremos que el Motín de Aranjuez rivalizó con el Dos de $\mathrm{Mayo}^{2}$ en los años inmediatamente posteriores a 1808 como fecha inicial de la revolución española. El 19 de marzo simbolizaba el fin de la tiranía (la caída de Godoy) y la subida al trono del monarca deseado. No es casualidad que la Constitución de Cádiz fuese proclamada un 19 de marzo de 1812.

Hablamos, eso sí, de un mito que se mantuvo vivo no más de un sexenio. Poco después del 4 de mayo de 1814 (fecha en la que Fernando VII, recién regresado a España, abolió la Constitución), los sucesos de Aranjuez adquirieron la imagen que hemos heredado. Si los absolutistas o "serviles" relegaron a un segundo plano el golpe de Estado que había llevado a su rey hasta el trono, por su parte, los liberales -en el exilio, durante el Trienio o desde el recuerdo bajo el reinado de Isabel II- fijaron las bases de lo que fue un motín cortesano urdido por los fernandinos. Este es el paradigma que ha llegado hasta nosotros y que no pretendemos discutir ${ }^{3}$.

1 La bibliografía es amplia, y ya nos hemos referido a ella recientemente: CAlvo Maturana, Antonio y GonZÁlez Fuertes, Manuel A.: «Monarquía, Nación y Guerra de la Independencia: debe y haber historiográfico en torno a 1808», en LóPEZ-CORDÓN CORTEZO, Ma Victoria: Crisis intersecular y deslegitimación de Monarquías. Cuadernos de Historia Moderna, Anejo VII (2009), pp. 307-357.

2 Efeméride que ha despertado el interés de la historiografía reciente desde el punto de vista de su conmemoración y mitificación. Véanse, por ejemplo: Álvarez Barrientos, Joaquín (ed.): La Guerra de la Independencia en la cultura española, Madrid, Siglo XXI, 2008; Demange, Christian: El Dos de Mayo. Mito y fiesta nacional, 1808-1958, Madrid. Marcial Pons-CEPC, 2004; GARCÍA CÁrCel, Ricardo: El sueño de la nación indomable. Los mitos de la Guerra de la Independencia, Madrid, Temas de Hoy, 2007, pp. 95-124.

3 Paradigma tan asumido -y probablemente tan cierto- que el Motín de Aranjuez apenas despierta el interés de los historiadores actuales más que como epílogo del reinado de Carlos IV o prólogo de la Guerra de la Independencia La última monografía sobre el tema tiene ya cuarenta años: MARTí GiLABERT, Francisco, El Motín de Aranjuez, Pamplona, Eunsa, 1972. Existe algún artículo reciente como el firmado por el cronista de la ciudad de Aranjuez: Lindo Martínez, José Luis: "El Motín de Aranjuez, inicio de la Guerra de la Independencia: un acontecimiento histórico falseado", Ars et sapientia: Revista de la asociación de amigos de la Real Academia de Extremadura de las letras y las artes, 21 (2010), pp. 59-87. También se pueden encontrar referencias a este episodio en trabajos biográficos sobre Carlos IV, Manuel Godoy y Fernando VII (es el caso de: La PARra López, Emilio: Manuel Godoy, la aventura del poder, Barcelona, Tusquets, 2002, pp. 348-413). Para un análisis del Motín desde la perspectiva de la Guerra de la Independencia: EsDAILE, Charles: La Guerra de la Independencia: una nueva Historia, Barcelona, Crítica, 2002; y en el más amplio contexto del liberalismo español: Esdaile, Charles: La quiebra del liberalismo (1808-1939), Barcelona, Crítica, 2001. 
Nuestra intención es ofrecer los primeros pasos de un mito truncado, efímero y -quizá por eso- poco conocido: el de la "Revolución de Aranjuez".

\section{El Motín de Aranjuez visto por sus testigos (1808)}

Para los españoles contemporáneos a los hechos, los cambios producidos en 1808 fueron impactantes. Un súbdito de la Monarquía Hispánica difícilmente podía esperar llegar a tener tres monarcas en un año, ni una invasión militar. Aún más sorprendente debía resultar el vacío de poder y el cierto protagonismo popular en los hechos. Antonio Alcalá Galiano intentaba que sus lectores de finales del siglo XIX -"acostumbrados" a pronunciamientos y a cambios políticos- comprendieran lo extraordinario de los cambios que había vivido en su juventud:

La generación presente, para quien ha sido frecuente espectáculo el de los tumultos, mal puede comprender el efecto que hizo en nosotros en 1808 ver por primera vez campante la sedición, interrumpido el público sosiego y faltando el orden constante con que la autoridad mandaba y los súbditos obedecían ${ }^{4}$.

La élite estaba horrorizada al contemplar y sufrir la quiebra del orden establecido. El 21 de marzo, la condesa viuda de Fernán-Núñez escribió desde Madrid que «vivimos de milagro», que «todo está alborotado y estamos muertos» y que «estoy de tal modo que no puedo explicar» $»^{5}$. A la desconfianza hacia el pueblo llano se sumaba la incertidumbre provocada por la llegada del ejército francés; pero con el paso de los días, al ver que los saqueos sólo afectaban a Godoy y a su entorno ${ }^{6}$, los relatos de la época empezaron a demostrar su entusiasmo por el cambio de monarca y de gobierno. Un autor anónimo escribía el día del cese de Godoy por Carlos IV que «hemos tenido 6 u 8 días de la mayor consternación, pero se pueden dar por muy bien empleados a trueque de lograr uno como el de hoy, de un regocijo tan universal» ${ }^{7}$.

La impopularidad de Godoy era tan grande, que los contemporáneos vieron en el Motín de Aranjuez una revolución. En estos primeros compases no se percibió en absoluto como la revuelta de los privilegiados que conocemos. No se pensaba, por supuesto, en una revolución 8 "a la francesa" sino en un levantamiento contra el mal gobierno, no contra el rey. Hasta el momento de su abdicación, Carlos IV siguió

4 Alcalá Galiano, Antonio: «Memorias», en Obras escogidas de D. Antonio Alcalá Galiano (BAE, 83), Madrid, Atlas, 1955, p. 326.

5 CARAN (Centre d'accueil et de recherche des Archives Nationales, París), F7, 6.517b. Se trata de unas cartas de María de la Esclavitud Sarmiento, condesa viuda de Fernán Núñez, a su hijastro Camilo Gutiérrez de los Ríos. Véase: Calvo Maturana, Antonio: «"Dios nos libre de más revoluciones”: el Motín de Aranjuez y el Dos de Mayo vistos por la condesa viuda de Fernán Núñez», Pasado y Memoria (en prensa).

6 «La vista primera del desorden aterraba; pero, considerándolo mejor, se vio que no había peligro, salvo para la parentela y amigos íntimos del Príncipe de la Paz» (Alcalá Galiano, op.cit. (nota 4), p. 327). Véase: Rose DE VIEJo, I.: «La celebrada caída de nuestro coloso. Destrucciones espontáneas de retratos de M Godoy por el populacho», Academia, 47 (1978), pp. 199-226.

7 Relación de lo ocurrido en Madrid y Aranjuez en marzo de 1808, 1808. BN, R/63139.

8 La palabra "revolución" se utilizaba también para hablar de un tumulto o una revuelta. 
siendo vitoreado ${ }^{9}$. Las relaciones de los hechos presentan a un inocente príncipe Fernando. El protagonista de los cambios es el pueblo, es el que está intranquilo ante la marcha de los reyes, el que asalta la casa de Godoy, etc. (como mucho, se menciona a la guardia) ${ }^{10}$.

La entrada triunfal de Fernando VII en Madrid el 24 de marzo tranquilizó momentáneamente los ánimos. Todas las fuentes coinciden en la alegría generalizada por la proclamación del nuevo monarca. A decir de Blanco White: «nunca recibió monarca alguno tan sincera y cariñosa bienvenida de parte de sus súbditos» ${ }^{11}$. La condesa viuda de Fernán Núñez -cuyo hijo era uno de los hombres de confianza de Fernando VII- estaba entusiasmada con el nuevo rey: «Válgame Dios qué misión tan verdadera lo que hemos tenido por práctica» ${ }^{12}$. Ante la duda de si Napoleón aprobaría o no «lo que aquí se ha hecho», la misma señora tenía claro que en caso negativo "esto serían arroyos de sangre, pues todo el pueblo y nobleza se sacrificarían por su rey» ${ }^{13}$.

Son muchas las referencias a la grandeza de los días en los que cayó Godoy y ascendió Fernando VII. El 1 de abril, sin que hayan transcurrido ni dos semanas desde el Motín, «se habla mucho de que en Aranjuez se erigirá una colegiata para consagrar este monumento a la posteridad, que se nominará "Real Sitio de San José" porque dicho día salió la nación española del yugo y tiranía que por tantos años la afligió Manuel Godoy» ${ }^{14}$. Hablamos pues de un templo que conmemoraría la efeméride recordando a un patriarca tan importante como San José.

Por el contrario, el Dos de Mayo no fue percibido desde el principio como un día de extraordinaria importancia. Los madrileños que lo presenciaron destacaron sobre todo su carácter violento. Para la condesa viuda «el día 2 de este ha sido de

9 Así lo documentan varios manuscritos no necesariamente fernandinos. El viernes 18, ya caído Godoy: «A las siete de la mañana salieron de los balcones los Reyes y Príncipe N.S. y toda la Familia Real. Aquí empezó el pueblo un vitoreo general: viva el Rey, la Reina, el Príncipe de Asturias y la tropa. Los sombreros al aire y en la mano formaban una vista de las más agradables, junto con el llanto, con los sollozos y alegría de toda clase de gentes y sexos» (Diario de lo ocurrido en Aranjuez desde el día 13 de marzo de $1808,1808$. Manuscrito de la Biblioteca Nacional, R/60334). El 19 de marzo se oían estos gritos: «Viva el Rey, viva el Príncipe de Asturias. Muera Godoy, muera el traidor, muera el Choricero» (Relación de lo ocurrido en Madrid y Aranjuez..., op. cit. (nota 7)). Varios autores cuentan que las turbas llegaron a portar un retrato de Carlos IV como muestra de fidelidad.

10 A veces, dependiendo del momento y del narrador, un pueblo que representa los sentimientos de todos los españoles, y otras una masa irracional, crédula y violenta; el pueblo que derrocó a Godoy es del primer tipo, y el que hace los saqueos y debe ser calmado constantemente, del segundo. Las siguientes palabras de Álvarez Barrientos sobre la relación del actor Rafael Pérez son aplicables a otros relatos de aquel momento: «El verdadero protagonista del relato es el pueblo, a pesar de la importancia que tienen personajes individuales como Godoy (...) la familia real o determinados militares. Y es protagonista porque, además de narrar hechos y episodios de la guerra, se presentan sus contradicciones psicológicas, sus dudas e incertidumbres, sus deseos. El pueblo es el héroe que se subleva contra los franceses y que además da hasta lo que no tiene para contribuir a los gastos de la guerra, es la imagen grandiosa del grupo organizado y con un noble objetivo común; pero también es esa fuerza horrorosa (...) capaz de barbaridades como arrastrar a alguien por las calles hasta morir» (Álvarez Barrientos, Joaquín: «Introducción», en Pérez, Rafael: Madrid en 1808. El relato de un actor, Madrid, Biblioteca Histórica, 2008, p. 15).

11 Blanco-White, José Ma: Cartas de España, Sevilla, Fundación José Manuel Lara, 2004, p. 304.

12 Madrid, 30 de marzo de 1808. CARAN, F7, 6.517b.

13 Madrid, 31 de marzo de 1808. Ibidem.

14 Diario de lo ocurrido en Aranjuez..., op. cit. (nota 9). 
sangre, más de cinco mil han perecido» ${ }^{15}$; en los días sucesivos, el recuerdo de los hechos sólo le evocaba palabras como "sangre", "terrible" o "estremecimiento". Un autor anónimo -si bien proclive a los franceses- lo calificó como "lastimoso" y de "funestas consecuencias"16. En esta línea, el editor del relato del actor Rafael Pérez ha notado que este le dio mucha más importancia a los hechos de marzo en Aranjuez (doce páginas) que a los de mayo en Madrid (sólo una) ${ }^{17}$.

Tiene sentido que el recuerdo del Dos de Mayo fuera cobrando peso y utilidad con el paso de los meses, una vez conocidas las intenciones políticas de Napoleón y organizada la resistencia fernandina. En cambio, durante el Motín de Aranjuez, el "brazo popular" había derribado al odiado Godoy y había provocado el ascenso de un príncipe idolatrado; el efecto "revolucionario" se había percibido inmediatamente. Los madrileños no tenían perspectiva ni información para saber cuál era la cabeza pensante que manejaba a las masas en marzo, pero tampoco podían prever la guerra que esperaba a todos los españoles poco después de mayo. El paso del tiempo y los intereses políticos irían activando unos mitos y desactivando otros.

\section{Los primeros relatos impresos (1808)}

Una de las primeras obras impresas sobre el particular es el Manifiesto imparcial y exacto de lo más importante ocurrido en Aranjuez, Madrid y Bayona ${ }^{18}$. Se trata de un texto redactado con unos meses de perspectiva ${ }^{19}$, donde el autor reconoce que nadie esperaba las verdaderas intenciones de Napoleón y llega a admitir que el proyecto de Godoy de trasladar a la familia real era acertado ${ }^{20}$.

En esta relación de los hechos de «lo que se ha llamado revolución de Aranjuez», el pueblo sigue siendo el individuo que había sufrido la tiranía de Godoy por lealtad a su rey y que sólo se levantó por miedo a quedarse sin reyes, como «hijos tiernos que temen la ausencia de su padre» ${ }^{21}$. Incluso los saqueos de este pueblo idealizado fueron ejemplares: «acaso no presentarán las historias una revolución como esta, si así puede llamarse, en que no hubo más sangre derramada que la muy poca que destilaron las mejillas del príncipe de la Paz». Por supuesto, el nuevo rey colma de

15 Madrid, 8 de mayo de 1808. CARAN, F7, 6.517b.

16 Diario de lo ocurrido..., op. cit. (nota 9).

17 Álvarez Barrientos, op.cit. (nota 10), pp. 46-47.

18 Texto firmado con las iniciales "J. de A.", atribuido por algunos autores al intendente José de Arango. El catálogo de la Biblioteca Nacional considera que su autor es Juan de Arias.

19 «La mayoría de los escritos fechados en 1808, sobre todo en Madrid, fueron impresos entre julio y diciembre, en una situación completamente diferente a la de los meses anteriores, pues las tropas francesas habían evacuado Madrid y la insurrección había prendido en todo el territorio de la monarquía» (LA PARRA LÓPEZ, Emilio: «Fernando VII: impulso y freno a la sublevación de los españoles contra Napoleón», Mélanges de la Casa de Velázquez, 38-1, 2008, pp. 33-52).

20 «El suceso ha probado que era la única medida prudente en las circunstancias; pero propuesta por el Príncipe de la Paz no tuvo un solo partidario. No se reflexionó que las miras del malvado de Francia no podía conocerlas sino otro malvado» (Manifiesto imparcial y exacto de lo más importante ocurrido en Aranjuez, Madrid y Bayona. Desde 17 de marzo hasta 15 de mayo de 1808. Sobre la caída del príncipe de la Paz, y sobre el fin de la amistad y alianza de los franceses con los españoles, con licencia. Madrid, Repullés, 1808, p. 8).

21 Aunque Fernando tiene un pequeño papel en la trama al revelarle a un guardia la partida de la familia real (Ibidem, pp. 11-12). 
felicidad a los españoles: es «imposible pintar el alborozo de este pueblo viendo a su cabeza a un rey joven, amabilísimo y con todas las calamidades sobre que se pueden cimentar esperanzas lisonjeras $»^{22}$.

Conocidas ya las intenciones de los franceses e iniciada la guerra contra las tropas napoleónicas, el Dos de Mayo tiene un cariz distinto ${ }^{23}$. El autor del Manifiesto imparcial hace una pausa dramática al hablar de ese día («Mis nervios se convulsan..., mi corazón se estremece... ¡Día luctuoso! ¡Día eterno!... Recibe el tributo de mi sensibilidad patriótica en la interrupción misma de mi narración...» ${ }^{24}$ ). La fama de personajes vinculados a la glorificación de aquel día, como Daoíz y Velarde, aparece en el texto ( «no se pueden detallar las acciones heroicas, porque quizás fueron tantas... ${ }^{25}$ ). Los «héroes inmortales» eran ya ejemplo inspirador para la lucha contra Napoleón ${ }^{26}$. Palabras como "integridad", "libertad" e "independencia" se mezclan en un discurso con un llamamiento claro: "Fernando VII o la muerte, es la divisa de los españoles $\rangle^{27}$. Es normal que el relato comenzase en marzo de 1808 , momento en el que el monarca redentor había accedido al trono.

También se publicó en 1808 el Diario exacto o relación circunstanciada de lo acaecido en el Real Sitio de Aranjuez y Corte de Madrid, que parece un resumen impreso de un manuscrito ya citado ${ }^{28}$. Es significativo que el manuscrito detallase día a día todos los hechos ocurridos entre el 13 de marzo y el 10 de mayo, pero que sólo se imprimiese la parte correspondiente al Motín de Aranjuez (hasta el 20 de marzo). La mejor manera de legitimar el irregular ascenso al trono de Fernando era insistir en la tiranía del Príncipe de la Paz y en el carácter popular y espontáneo de la revuelta ${ }^{29}$. En las siguientes líneas se puede apreciar el valor que se le dio y se le quiso dar a la caída de Godoy a manos «del pueblo»:

Viernes 18 [de marzo]. Hoy se puede decir que amaneció el Iris de Paz para toda la vasta extensión de la Monarquía Española; día memorable que hará época en la posteridad y se debía señalar en las notas cronológicas del Reino como una de las más

22 Ibid., pp. 14-15.

23 Ya en 1808, Antonio Capmany -poco después un liberal moderado en las Cortes de Cádiz-mostró su preferencia por el Dos de Mayo aún reconociendo el valor de ambas fechas: «El enojo desplegado en Aranjuez contra Godoy os entreabrió una puerta a la esperanza y el funesto día dos de Mayo, memorable en los fastos de Madrid y en los anales de nuestra nación, os la abrió de par en par a la venganza» (CAPMANY, Antonio: Centinela contra franceses, ed. de Françoise Étienvre, London, Tamesis Book Limited, 1988).

24 Manifiesto imparcial y exacto..., op.cit. (nota 20), p. 25.

25 Ibidem, p. 27.

26 «¡Españoles! ¿No oís los clamores de aquellas víctimas interesantes? Los oís, ¿y respondéis con una compasión estéril?» (Ibid., p. 32)

27 Ib., p. 38 .

28 Diario de lo ocurrido en Aranjuez desde el día 13 de marzo de 1808, 1808. BN, R/60334.

29 Ambos elementos (las malas artes de Godoy y el carácter espontáneo del Motín de Aranjuez) aparecen en la Exposición del fernandino Cevallos: «a la manera de una explosión inesperada sucedieron repentinamente los movimientos de Aranjuez el 17 y 19 de marzo, en los que el pueblo fue conducido por una especie de instinto de su conservación y cuyo resultado fue la prisión del Privado, que sin el título de Rey había ejercido, por decirlo así, exclusivamente y por muchos años las funciones de tal» (Cevallos, Pedro: Exposición de los hechos y maquinaciones que han preparado la usurpación en la Corona de España y los medios que el emperador de los franceses ha puesto en obra para realizarla, Cádiz, Reimpreso por D. José Niel, 1808, p. $11)$. 
singulares y extraordinarias de la Historia. Huyó el tirano y opresor de la humanidad nacional ${ }^{30}$.

En uno de los muchos pequeños impresos típicos de aquellos años, titulado Gazeta del Infierno, la fecha del 19 de marzo aparece junto a las palabras "Gloria celestial”. El periódico de Satán informaba con pesar de que, en esta fecha, Dios había firmado la paz con España, lo que ponía en peligro los planes del aliado diabólico (Napoleón) ${ }^{31}$. Otro texto, publicado para refutar la visión que El Argos francés había ofrecido del marzo y el mayo españoles, recordaba que fue «el 19 de marzo» cuando «el pueblo dio el primer paso de su independencia», momento en el que «declinó para siempre la gloria y la fortuna de Godoy» ${ }^{32}$.

Son muchos los textos publicados en 1808 que comparten la imagen libertadora de lo que hoy conocemos como "Motín de Aranjuez", que entonces se consideró mucho más que un motín. Vicente Labaig y Lassala es el autor de un sermón en acción de gracias a San José por la defensa de Valencia contra el ejército francés de Moncey. Labaig rememoraba el 19 de marzo de aquel año, onomástica de dicho santo, como el día de la victoria sobre la tiranía (la de Godoy e incluso la de Napoleón) gracias al «movimiento popular de Aranjuez»:

El día 19 de marzo del presente año, consagrado a la solemne memoria de este Patriarca excelso, ¿no será en todos los siglos el día de la libertad de España cautiva, el día de la ignominia de la Francia orgullosa, el día del honor, el día de la verdad, el día de la justicia? Día en que desaparecieron los engaños, se destruyeron las perfidias y se desarmaron las conjuraciones ${ }^{33}$.

En estos textos de principios de la guerra, era el 19 de marzo y no el Dos de Mayo el hito que se relacionaba con la defensa contra los franceses. Vicente Labaig utilizaba una cita bíblica para ensalzar el 19 de marzo: «El día de la victoria celebrada con esta festividad, será recibido en el número de nuestros días santos desde aquel tiempo hasta los días últimos» ${ }^{34}$. En el próximo apartado trataremos de explicar por qué los liberales (sobre todo los más radicales) prefirieron cargar las tintas sobre el Dos de Mayo, pero tiene sentido que fuese el día del ascenso del adorado Fernando (unido a la caída en los días previos de Godoy) el escogido como referente de la lucha.

\footnotetext{
30 Diario exacto o relación circunstanciada de lo acaecido en el Real Sitio de Aranjuez y Corte de Madrid de resultas de haber creído el Pueblo que SS.MM. querian dejar la capital, prisión (...) del Príncipe de la Paz y Coronación del Príncipe de Asturias, ahora Fernando VII, reimpreso en Cádiz, en la Imprenta de la viuda de don Manuel Comes, 1808. BN R/60163(4).

31 Gazeta del Infierno de 13 de agosto de 1808. BN R/60378(17).

32 El Argos refutado: impugnación al papel sedicioso, que baxo este título se publicó en el periódico publicista francés, sobre los acontecimientos de Aranjuez y del 2 de mayo, 1808. BN 1/247332.

33 Labaig y Lassala, Vicente Facundo: Sermón el acción de gracias al Patriarca San José por la defensa de Valencia contra el ejército francés día 28 de junio 1808 y en reconocimiento a la protección del mismo santo invocada sobre los heridos en el combate, Valencia, Imprenta de Salvador Faulí, 1808, p. 19. La obra debió de ser publicada en los dos últimos meses de 1808, ya que menciona la proclamación de la Junta Suprema Central, el 25 de septiembre. Está dedicada a Fernando VII, y utiliza el paralelismo fernandino entre Godoy el bíblico Amán.

34 Ibidem, p. 9.
} 
La Representación de Fernando a su padre Carlos IV en 1807, conoció varias ediciones en 1808. En una de las versiones, el editor -un liberal que firma como "el Aragonés"- añadió un prólogo que establece «la revolución de Aranjuez de 19 de marzo» como la «época verdadera de nuestra libertad y señal augusta de las grandes empresas y triunfos inmortales a que se preparaba el pueblo español». Era el final de «20 años de tiránica e inepta administración» y el ascenso al «trono español [d] el Príncipe que amaba el pueblo». Según "el Aragonés", si Godoy hubiese caído en 1807 habría mejorado «prodigiosamente la suerte de la nación, llegando entonces a la libertad y a la independencia sin las convulsiones, la devastación y la sangre con que ahora se rescata de la más injusta y vergonzosa esclavitud» ${ }^{35}$.

Otro texto del mismo año comparaba las revoluciones española y francesa. De nuevo, el Motín de Aranjuez era interpretado como el día de la liberación de los españoles, el momento en el que: «la incomparable lealtad española, que respetando la voluntad de su Rey, había sufrido tanto tiempo el odioso ministro, no pudiendo resistir más a los clamores de la patria, derriba al formidable coloso con aquel ímpetu que es propio de la nación $»^{36}$.

El mismo Manuel José Quintana publicó en 1808 un poema dedicado A España después de la revolución de marzo. El texto, un llamamiento a la lucha contra los franceses, recuerda el padecimiento de los españoles bajo los reyes tiranos. Quintana ubicó en "los márgenes del Tajo" ${ }^{37}$ el inicio de la lucha española contra la tiranía:
«Estremeciose España
Del indigno rumor que cerca oía,
Y el grande impulso de su justa saña
Rompió el volcán que en su interior hervía.
Sus déspotas antiguos
Consternados y pálidos se esconden:
Resuena el eco de venganza en torno,
Y del Tajo los márgenes responden:
“¡Venganza!” ¿Dónde están, sagrado río,
Los colosos de oprobio y de vergüenza
Que nuestro bien en su insolencia ahogaban?
$\mathrm{Su}$ gloria fue, nuestro esplendor comienza;
Y tú orgulloso y fiero,
Viendo que aún hay Castillas y castellanos,
Precipitas al mar tus rubias ondas
Diciendo, "ya acabaron los tiranos" $"{ }^{38}$.

El "Prospecto" del Semanario Patriótico, periódico fundado por el propio Quintana, atribuía a una entidad típicamente liberal como «la opinión pública» todos los

35 Representación del príncipe de Asturias Don Fernando (ahora nuestro Rey y Señor) a su padre Don Carlos IV, hallada entre los papeles de S.A.R., escrita toda de su mano en octubre de 1807. Publícala un patriota aragonés, Valencia, Imprenta de José de Orga, 1808, pp. XIII-XVII. BN R/60163.

36 Revolución francesa y española. Origen y progresos de las dos hasta la época presente, por un patriota portugués, Málaga, D. Luis Carreras e hijos, s.a. BN R/60234(2).

37 Expresión que alude por igual a Aranjuez y a España.

38 Quintana, Manuel José: Poesias patrióticas, Madrid, Imprenta Real, 1808, p. 21. 
sucesos extraordinarios de 1808, los de Aranjuez incluidos. Esta fue «la que derribó al Favorito insolente que por veinte años estuvo insultando a la Nación, la que puso en el trono a un Príncipe idolatrado del pueblo que veía en él un compañero de su opresión y el árbol de la esperanza, y la que ha producido los prodigios de valor que con espanto y admiración de Europa acaban de obrar nuestras Provincias» ${ }^{39}$.

Para cerrar este apartado, recurramos a un impreso curioso, también de 1808. Se trata de un homenaje a Diego Ángel Moraleja, el hombre que descubrió a Godoy, escondido en su palacio de Aranjuez desde que las turbas lo tomaron. El texto lo pone como ejemplo del «patriotismo» y el «celo» con el que sus convecinos debían enfrentarse a los franceses. Una vez más, es la caída de Godoy el detonante de la libertad española y el 19 de marzo su punto de partida:

En una época en que no se oye otra voz que la de patriotismo (...) ¿quién podrá presentar unos títulos más auténticos, ni modelos más vivos que vosotros afortunados habitantes de Hinojosos, que abrigáis en vuestro seno al héroe regenerador de la Nación y al autor de nuestra libertad y la del Trono español? ${ }^{40} \mathrm{~A}$ aquel que no perdonó medio hasta asegurar por sí mismo al monstruo horrendo, que es el origen de todos nuestros males ${ }^{41}$.

El autor no se olvidaba de pedir a sus lectores que hicieran «obsequiosos cultos al patriarca San José». Es importante insistir en estas alusiones a la caída de Godoy y a su relación con la lucha española contra el tirano Bonaparte para entender que, cuando la Constitución de 1812 se proclame un 19 de marzo, esa fecha no sólo supondrá un homenaje al ausente Fernando VII, sino una conmemoración de la lucha contra el despotismo.

\section{Los años inmediatos y la interpretación liberal (1809-1811)}

Casualmente, el 19 de marzo era motivo de fiesta en el bando "afrancesado" al coincidir con la onomástica de José $\mathrm{I}^{42}$. La Gaceta de Madrid y otros impresos ${ }^{43}$ aluden a los besamanos en la Corte, misas, salvas de artillería, indultos, obras de caridad, representaciones teatrales, luminarias, repiques de campana, etc. con los que se celebraba el día del rey Bonaparte.

En el bando "patriota" o fernandino, la Junta Suprema Central acabaría por conmemorar el Dos de Mayo por encima del 19 de marzo, pero el culto al levantamiento

39 "Prospecto", Semanario Patriótico, I (1808).

40 [A pie de página en el original] «Diego Ángel Moraleja, fue el primero que descubrió a Godoy en donde estaba oculto, y le puso preso a la vista del rey, de la tropa y servidumbre de la Casa Real» (Prisión de Godoy por Diego Ángel Moraleja en 19 de marzo de 1808 en su guardilla de su casa del Real Sitio de Aranjuez, 1808, p. 1).

41 Ibidem, pp. 1-2. BN R/60378(8).

42 Sin duda, la importancia de San José para los cristianos hacía que esta fecha fuese importante en ambos bandos. A buen seguro, los diputados de Cádiz tuvieron en cuenta la importancia religiosa de esta fecha.

43 Programa para la festividad de los dias del Rey Nuestro señor Don Josef Napoleón I, 1812. BN R/60016(1); o Andeyro y Aldao, Pablo de: Sermón que en presencia del Rey D. José Napoleón $1^{\circ}$ predicó en esta Catedral de Granada: el día 19 de Marzo de 1810, ca. 1810. BN R/60941. 
madrileño aún no estaba asentado en su primer cumpleaños. Un texto fechado el 11 de mayo de 1809 pedía a los españoles que honrasen a las víctimas de Murat en la extraña fecha del 16 de ese mes, dos semanas después del verdadero aniversario ${ }^{44}$. Esta improvisación demuestra que la idea de celebrar el aniversario del Dos de Mayo era bastante reciente. Unos meses antes, el 1 de enero de 1809, la Junta había publicado el Manifiesto de la Nación Española a la Europa, que relataba la traición napoleónica a su aliado español. Este texto menciona el «suceso memorable del 2 de mayo», pero lo describe como un «funesto día» provocado por los franceses para hacerse con la capital a costa de los valientes madrileños ${ }^{45}$. No tiene menos protagonismo en el Manifiesto (más bien lo contrario) el derrocamiento del tirano Godoy y el ascenso al trono de Fernando VII, detonantes del renacimiento nacional:

Este fue el término de la paciencia española, que ya se vio en el caso de no tener esperanzas a que acogerse ni respetos que guardar. Mirose el pueblo desamparado de sus Príncipes, sin gobierno, sin protección, abandonado a la merced de los extranjeros y expuesto a la suerte de Portugal (...) Alzó pues la voz y no consintió en la partida de la Familia Real: el favorito cayó precipitado a la nada, de donde jamás debió salir, y sus protectores, no queriendo o no sabiendo reinar sin él, abdicaron el trono en su heredero. Fernando VII fue solemne y generalmente aclamado y reconocido Rey por el pueblo que le había de obedecer. La nación se vio súbitamente renacer de muerte a vida, la confianza volvió a reinar en los corazones y la felicidad y la alegría rebosaban en todas partes. Ningunos más bien que los franceses pueden, si quieren alguna vez hablar la verdad, deponer de esta unanimidad de sentimientos, de este gozo universal, de estas aclamaciones y aplausos verdaderamente nacionales ${ }^{46}$.

Aún así, los liberales fueron mostrando cierta preferencia por el Dos de Mayo, que suponía un levantamiento popular contra el invasor francés, antes que el 19 de marzo, fecha en la que había accedido al trono un monarca absoluto. Los progresistas llegaron a la conclusión de que la ausencia de Fernando podía ser una ventaja, al no haber interferencias para crear una constitución. Quintana animaba a las Cortes a aprovechar «la ocasión gloriosa que nos presenta la fortuna» para acabar con tres siglos de sometimiento a «la voluntad caprichosa de uno solo» y poner a la nación «a cubierto en delante de toda clase de tiranía» ${ }^{47}$.

En unas ficticias conversaciones de Fernando VII con un soldado, el idealizado rey se mostraba entusiasmado con los trabajos de las Cortes de Cádiz y llegaba a admitir que su presencia en España habría sido un lastre para tan gloriosa empresa:

44 Los caídos en el Dos de Mayo eran recordados como «fundadores de la libertad española»y «los primeros que arrojaron el grito contra la opresión extranjera y sellaron con su sangre el voto nacional de la independencia». Todo español que desfalleciese en su lucha contra el enemigo debía recordar a los «patriotas de Mayo», «mártires de la Patria» (BN R/60292, 9).

45 Manifiesto de la Nación Española a la Europa, reimpreso de orden de la Junta Superior de Observación y Defensa de este Reino, Valencia, Viuda de Martín Peris, 1809, pp. 9-10.

46 Ibidem, pp. 7-8.

47 Quintana, Manuel José: España libre: Discurso de un español a los diputados de Cortes, Mallorca, Imprenta Real, 1810, pp. 1-5. 
Tal vez se ha necesitado que la España descendiese al borde del sepulcro para poder sancionar sus leyes fundamentales. Quizá si yo estuviera presente, la intriga y la adulación, que nunca se separan de los palacios de los príncipes, serían el más fuerte impedimento al logro de una constitución tan liberal. Acaso yo mismo sería involuntariamente arrastrado de las pérfidas sugestiones de la lisonja ${ }^{48}$.

Emilio La Parra considera que fue Flórez Estrada quien marcó la pauta interpretativa del Dos de Mayo ${ }^{49}$. En su Introducción para la Historia de la Revolución de España (1810), el autor liberal situó en este mes el punto de partida de la «revolución general de España» ${ }^{50}$. Para él, la «conmoción de Aranjuez» había sido una oportunidad perdida. El pueblo «se contentó con el estúpido gozo de ver a Fernando en el trono sin advertir que este podría abusar de su poder del mismo modo que había abusado su padre». A causa de su ignorancia, los españoles habían hecho «la guerra al tirano sin pensar en hacerla a la tiranía ${ }^{51}$.

En todo caso, se puede decir que autores de tendencia política dispar siguieron recordando el 19 de marzo en los años inmediatos al Motín. Era un lugar común decir de diversas maneras que el gobierno del Príncipe de la Paz fue una «tiranía sorda y exterminadora» ${ }^{52}$ y que con Fernando VII «recibió [España] de la Providencia un restaurador» ${ }^{53}$. Ignacio Garciny publicó en 1811 su Quadro de la España, donde llamaba a Godoy "monstruo" e incluso tildaba de déspota al supuestamente bondadoso y dócil Carlos IV. Para este autor -que aspiraba a parecer el fernandino más fiel para limpiar su fama de afrancesado- «el memorable acontecimiento del 19 de marzo de 1808, que puso la Corona en las sienes de nuestro muy amado Monarca Don Fernando VII (...) hará época en los fastos de la Historia» ${ }^{54}$.

E1 26 de abril de 1811, el "Prospecto" de la Gaceta de la Junta Superior de la Mancha ensalzaba a los manchegos que se lanzaron contra la casa de Godoy el 17 de marzo, como la capital hacía con los madrileños del 2 de mayo. Aranjuez vio «hecho pedazos el nudo de oprobio que se creía indisoluble, vio descender del trono al anciano monarca (...) vio deshecho en humo el imaginario principado de los Algarves, y vio las sienes del amado Fernando ceñidas con la corona que la divina providencia y el amor de los españoles le tenían preparada». El «heroísmo» manchego había sido «la muestra de lo que podía prometerse la patria de los habitantes de esta provincia ${ }^{55}$.

48 Conversaciones con Fernando VII en Valençey con un oficial español prisionero, fugado del deposito de Maçon, Isla de León, Oficina de Periu, 1812, p. 6. BN, R/60163(6) y (7).

49 LA PARra, op. cit. (nota 19), nota 1.

50 Otro asturiano y diputado de las Cortes de Cádiz, José Canga Argüelles, escribió que «en el mes de mayo de 1808» la «Nación española (...) juró su independencia» (CANGA ArgüELlES, José: Reflexiones sociales, o idea para la constitución española, que un patriota ofrece a los representantes de Cortes, Valencia, Imprenta de Don José Esteban, 1811, p. 1).

51 Flórez Estrada, A.: «Historia de la Revolución de España», en Obras Completas, ed. de M. Artola, BAE, 113, vol. II, Madrid, Atlas, 1958, pp. 237-241.

52 [Atribuido a Antillón, Isidoro de: ¿Qué es lo que más importa a la España? Discurso de un miembro del populacho, Cádiz, Imprenta de la Viuda de D. Manuel Comes, s.a., p. 1. BN R/60292(73).

53 Política, s.1., s.a., p. 6. BN R/60292(50).

54 Garciny, Ignacio: Quadro de la España desde el reinado de Carlos IV. Memoria de la persecución que ha padecido Don Ignacio Garciny..., Valencia, Imprenta de D. Benito Monfort, 1811, p. 17.

55 "Prospecto", Gaceta de la Junta Superior de la Mancha, 1 (26 de abril de 1811). 
Como vemos, la imagen idealizada del Motín de Aranjuez no se perdió tan pronto, por el contrario estuvo muy presente en las Cortes de Cádiz, objeto del próximo apartado.

\section{El Motín de Aranjuez y las Cortes de Cádiz}

No podemos olvidar que Fernando VII era también el rey de los liberales, y que su nombre encabezó la Constitución ${ }^{56}$. Es normal, por tanto, que -al menos- los más moderados quisieran ver en su ascenso al trono un movimiento popular que inició la revolución española ${ }^{57}$.

Es difícil saber hasta qué punto los diputados de Cádiz creían en las convicciones constitucionalistas del monarca. Acaso querían pensar, como recordaba Alcalá Galiano, «que un rey subido al trono por el poder popular, por su propia voluntad o a despecho, habría de satisfacer a ciertas condiciones, o de sujetarse a ciertas consecuencias de su encumbramiento ${ }^{58}$. Para defenderse de las acusaciones de los llamados "serviles", muchos liberales gaditanos se esforzaban en demostrar su fidelidad a Fernando VII y la verosimilitud del talante progresista del rey ausente. Las citadas Conversaciones de Fernando VII (Isla de León, 1811) no fueron el único caso. Se publicaron en Cádiz varias obras que intentaban desmentir la idea de que la Constitución traicionaba al monarca. Una carta dirigida a Fernando y fechada el 19 de marzo de 1812 pretendía hacer ver que el rey tenía pensado hacer reformas para librar a la nación y a su sucesor de «la arbitrariedad del rey», pero que no tuvo tiempo de convocar Cortes, «que son la verdadera representación Nacional» ${ }^{59}$ (hay más ejemplos en este sentido ${ }^{60}$ ).

Centrándonos ya en el Cádiz constitucional, podemos decir que el recuerdo del Motín de Aranjuez tuvo un peso considerable. Es cierto que el Discurso preliminar de la Constitución, si bien se refería a la tiranía de los gobiernos de Carlos IV ${ }^{61}$, no

56 Así comienzo el bien conocido texto constitucional: «DON FERNANDO SÉPTIMO, por la gracia de Dios y la Constitución de la Monarquía española, Rey de las Españas y en su ausencia y cautividad la Regencia del reino, nombrada por las Cortes generales y extraordinarias...» (Constitución Política de la Monarquía Española promulgada en Cádiz a 19 de marzo de 1812, Cádiz, Imprenta Real, 1812). Con motivo del segundo centenario de la Constitución de Cádiz se están publicando numerosos trabajos. Véase, por ejemplo: EsCUDERO, José Antonio (dir.): Cortes y Constitución de Cádiz (200 años), Madrid, Espasa, 2011, 3 vols.

57 Salmón, Manuel: Resumen histórico de la revolución de España, Cádiz, Imprenta Real, 1812.

58 Alcalá Galiano, op.cit. (nota 4), p. 329.

59 Espejo Bermudo, José Joaquín: A la Magestad Católica de D. Fernando VII: Carta escrita en Cádiz el día diez y nueve de marzo de este año, Cádiz, Imprenta de D. José Antonio Niel, 1812. BN R/61224.

60 Por ejemplo, un impreso explicaba que: «Tan Jacobino es quien quiera establecer en España el gobierno republicano, minando el trono de Fernando VII, a quien las mismas Cortes aman y veneran, como lo es aquel, que con pretexto de defender al Rey quiere minar la soberanía de las Cortes y poner en duda su legitimidad» (Nuevo y funesto síntoma de la epidemia llamada diarrea de las imprentas, Cádiz, Oficina de la Viuda de Comes, 1811, pp. 25-26).

61 «La funesta política del anterior reinado había sabido desterrar de tal modo el gusto y afición hacia nuestras antiguas instituciones comprendidas en los cuerpos de la jurisprudencia española descritas, explicadas y comentadas por los escritores nacionales a tal punto que no puede atribuirse sino a un plan seguido por el Gobierno la lamentable ignorancias de nuestras cosas» (Discurso preliminar leido en las Cortes al presentar la Comisión de Constitución el proyecto de ella, Cádiz, Imprenta Tormentaria, 1812, p. 6). 
aludía directamente a las circunstancias de la proclamación de Fernando VII. No negaremos tampoco la preferencia de los liberales por el Dos de Mayo que, en la sesión de Cortes coincidente con su tercer aniversario, fue elevado a los altares de la memoria histórica ${ }^{62}$. Pero vamos a ver en las próximas páginas hasta qué punto estuvo presente el recuerdo del 19 de marzo tanto en la prensa gaditana como en las mismas Cortes.

La prensa gaditana hizo numerosas referencias a la proclamación de Fernando VII. Si el liberal Conciso recordaba en 1811 el tercer aniversario de la entrada del monarca en Madrid; no se quedaba atrás el "servil" Censor General, que la consideraba una fecha de la «más grata conmemoración para todos los legítimos españoles» ${ }^{63}$. A principios de 1812, El Conciso había tomado la curiosa iniciativa de numerar los años «de la gloriosa lucha del pueblo español contra la tiranía», iniciando "a la francesa" los un nuevo calendario según los años transcurridos desde el inicio de la revolución española:

Entramos en el año V de nuestra gloriosa insurrección contra la tiranía. En marzo de 1808 derribamos el coloso doméstico, y previmos que había que luchar contra otro extranjero. El 2 de mayo se rompió el velo (...) Ya a este tiempo, el tirano extranjero había comprado del doméstico las principales plazas (...) ya cautivo el amado Fernando (...) El año de 1812 es el quinto año, en que seguimos esta asombrosa lucha (...) ¿Qué hemos hecho?... NADA, sino entrar en el V año de lucha ${ }^{64}$.

Dentro de las Cortes no se olvidaron de los sucesos de Aranjuez, todo lo contrario. En las Actas Secretas podemos leer que en la sesión del 10 de febrero de 1812 un grupo de diputados hizo una propuesta con las solemnidades que debían acompañar a la publicación de la Constitución para que fuese «el día grande de la Nación Española» ${ }^{65}$. Una comisión se encargó de estudiar dicho asunto y decidió que «sería muy oportuno que la promulgación de esta gran Carta, que debe fijar la prosperidad de la Nación, tuviese efecto en alguno de los días más señalados de nuestra santa insurrección, y determinadamente en el 19 del actual mes de marzo, cumpleaños del advenimiento al trono del Rey amado de todos los españoles, D. Fernando VII, por la espontánea renuncia de Carlos IV su padre, y del derrocamiento para siempre del régimen arbitrario del anterior Gobierno» ${ }^{66}$.

62 A propuesta de Evaristo Pérez de Castro (y con algún matiz propuesto por Capmany) se aprobó por unanimidad: "Que en el calendario se señale con letra cursiva el día 2 de Mayo: Conmemoración de los difuntos, primeros mártires de la libertas española en Madrid». Se aprobó igualmente que lo nombres de Daoíz y Velarde fuesen «inscritos con letras de oro» en unas tablas que se colocarían en la sala de sesiones (Diario de Sesiones de las Cortes Generales y Extraordinarias, no 213, día 2 de mayo de 1811). Ese mismo día, se hizo del 2 de Mayo una fiesta nacional al pedir a todas las iglesias y pueblos de la Monarquía la celebración de cada aniversario. Se trata del decreto LXII de 2 de mayo de 1811 (Colección de los decretos y órdenes que han expedido las Cortes Generales y Extraordinarias desde su instalación en 24 de septiembre de 1810 hasta igual fecha de 1811, Cádiz, Imprenta Real, 1811, pp. 138-140).

63 El Censor General, 3 (1811), pp. 52-53.

64 El Conciso, 1 (miércoles 1 de enero de 1812), pp. 3-4.

65 Actas secretas de las Cortes (10 de febrero de 1812), pp. 560-561.

66 Ibidem (8 de marzo de 1812), p. 586. 
No hay duda, el 19 de marzo era considerada una fecha señalada de la «santa insurrección». Pero era igualmente importante por el ascenso de Fernando VII y por la caída de Godoy. Llama la atención que el día 18 de marzo también fuese planteado como posible ${ }^{67}$. Recordemos que en ese día de 1808 fue exonerado Godoy, pero Carlos IV era aún rey. Esta posibilidad otorgaría mayor importancia al fin de la supuesta tiranía del Príncipe de la Paz que al gobierno de Fernando. El antihéroe Godoy, vituperado hasta el extremo por aquellos años, forma parte -como legendario antagonista- de la base del liberalismo español.

Ya en sesión pública, el 11 de marzo de 1812 se confirmó la viabilidad de ambas fechas, «que abrieron un largo campo a las esperanzas de la Nación y a los heroicos hechos de su lealtad y patriotismo», aunque con la preferencia del 19. Finalmente, como es sabido, el 18 se leyó la Constitución, la firmaron los diputados y se presentó a la Regencia. El 19 se juró la Carta Magna y se celebraron todos los actos planeados. En el discurso de este día, el Presidente del Congreso mostró su satisfacción porque se hubiesen terminado los trabajos a tiempo «para firmarla ayer y hacer hoy la jura y publicación, cuanto que ambos son días muy señalados, por haberse roto en ellos las cadenas de la esclavitud y concurrir además en el presente al aniversario de la exaltación al Trono de nuestro adorado Rey el Sr. D. Fernando VII». El recuerdo del odiado Godoy (cuyo nombre está implícito), chivo expiatorio de los males de una Monarquía invadida por otro déspota, era el ejemplo moralizante que justificaba la Constitución, evitando así «a la Nación y a todos los individuos que forman esta gran sociedad el verse otra vez sumergidos en las tristes desgracias a que los ha conducido la arbitrariedad y la tiranía» ${ }^{6}$.

La buscada coincidencia de la proclamación de la Constitución de Cádiz el 19 de marzo no se refleja en todas las cabeceras gaditanas de $1812^{69}$. Será El Conciso el periódico que aluda al aniversario de Aranjuez citando el discurso del presidente de las Cortes y recordando que fue «en los célebres días 18 y 19 de Marzo de 1808» cuando «se rasgó el velo que hasta entonces había cubierto los acontecimientos políticos, y la nación empezó a recobrar sus imprescriptibles derechos» ${ }^{70}$.

Mientras dure el imposible idilio Cortes-Fernando VII, las glosas por el aniversario de la Constitución incluirán los hechos de marzo de 1808. El paralelismo entre ambas fechas - «el aniversario de nuestra primera señal de vida y de la proclamación del código fundamental del Estado» ${ }^{71}-$ hacía del texto constitucional el garante de

67 «Si en el día 19 se encontrase algún inconveniente, podría hacerse el 18, que también forma época con el anterior 17, por la feliz revolución de Aranjuez, que precedió al advenimiento al Trono de nuestro Monarca actual» (Diario de Sesiones de las Cortes Generales y Extraordinarias, nº 517, día 11 de marzo de 1811, p. 2.901).

68 Ibidem.

69 En ese día, El Diario Mercantil de Cádiz aprovechó el día de San José para publicar unos versos contra José I. Sólo al final del número se puede leer: «Hoy se publica en Cádiz la Constitución Española, a despecho de los franceses y de los serviles». La Abeja Española se refirió con entusiasmo a la Constitución, pero sin siquiera mencionar a Fernando VII ni a los sucesos de cuatro años antes: «Tengamos siempre presente que el 19 de marzo de 1812 juramos morir antes que renunciar otra vez a los derechos que reconquistábamos a la tiranía que nos había degradado y envilecido»».

70 El Conciso, 20 (20 de marzo de 1812).

71 El Redactor General, 643 (19 de marzo de 1813), p. 2.587. 
que no habría más "Godoys” en España («he aquí el precioso código que os pone a cubierto de los desafueros de los reyes, de sus ministros y favoritos» ${ }^{73}$ ). El 19 de marzo de 1813, El Redactor General hizo una reseña del aniversario de las Cortes de Cádiz similar a la que había hecho del Dos de Mayo el año anterior. Tenían en ella los hechos de Aranjuez incluso mayor protagonismo que la Constitución:

El 19 de marzo de 1808 debe ser para los españoles día de bendición. En él alzó la cabeza el genio del patriotismo y dando la señal de reunión proclamó a un tiempo, aunque silenciosamente, odio al despotismo, muerte a los tiranos ${ }^{74}$.

Podemos encontrar en los Diarios de Sesiones de las Cortes algún pequeño homenaje a este episodio histórico (un peldaño por debajo, insistimos, respecto al entusiasmo que despertaba en los diputados el Dos de Mayo). El 29 de abril, las Cortes admitieron una estampa «de lo ocurrido en Aranjuez el 19 de Marzo de 1808» ${ }^{75}$. Trasladadas las Cortes a Madrid ${ }^{76}$, el diputado Echeverría pidió el 19 de marzo de 1814 que se hiciera un reconocimiento a los madrileños colocando «en el salón permanente de Cortes un monumento capaz de transmitir la gloriosa memoria del 19 de marzo de 1808 hasta la más remota generación con una inscripción que diga: "El pueblo español de los dos mundos consagra al heroico de Madrid este triunfo digno de su valor, constancia, fidelidad y patriotismo». El diputado se reservaba la posibilidad de hacer la misma petición el día Dos de Mayo, «por ocupar el primer lugar entre los fastos de la historia de España y demás naciones» ${ }^{77}$.

La petición de Echeverría fue aprobada por unanimidad. También se aprobó aunque no consta la unanimidad- la propuesta de los diputados Abella y Norgaray, pidiendo que, al ser «el día de hoy el más señalado de España, y particularmente del noble y leal pueblo de Madrid», lo honrasen las Cortes «con una gracia particular». El mismo día, Canga Argüelles quiso homenajear igualmente a los madrileños pero con un programa de fastos exclusivamente centrados en el Dos de Mayo, que fue acogido por todos los diputados ${ }^{78}$. La Regencia unió todas estas peticiones y publicó un decreto el 24 de marzo en el que se honraba principalmente el Dos de Mayo, pero en el que había un hueco para la convocatoria de un premio para la realización de una estatua «capaz de eternizar la memoria gloriosa para Madrid del día 19 de Marzo de $1808 \gg^{79}$.

72 En su último número, coincidiendo con la proclamación constitucional, el Semanario Patriótico vinculaba a los serviles con «los panegiristas del sátrapa Godoy y de los venales gaceteros del sangriento corso» (Semanario Patriótico, CII, 19 de marzo de 1812, p. 381).

73 El Redactor General, 643 (19 de marzo de 1813), pp. 2.587-2.588.

74 Ibidem, p. 2.587.

75 Diario de Sesiones de las Cortes Generales y Extraordinarias, no 837, 28 de abril de 1811, p. 5.133.

76 La presencia de las Cortes en Madrid fue fundamental para ambos homenajes. En las celebración gaditana del segundo aniversario de la Constitución no se menciona ninguna de las dos fechas (Cádiz, Imprenta del Redactor General, 1814. BN R/60016).

77 Diario de Sesiones de las Cortes Generales y Extraordinarias, no 25, 19 de marzo de 1814, p. 146.

78 Ibidem.

79 Cit. por Gómez de Arteche, José: El luto del Dos de Mayo. Monografía histórica, Madrid, Imprenta y Litografía del Depósito de Guerra, 1884, p. 28. 
El Conciso celebró el sexto aniversario de Aranjuez y el segundo de la Constitución con el modelo de discurso que ya conocemos. Madrid y Cádiz eran dos ciudades que habían alumbrado la «libertad española (...) aquel declarándose contra la tiranía, este proclamando principios de eterna verdad contra toda clase de tiranos». Buena parte del texto recuerda el levantamiento del «pueblo» contra el «déspota Godoy (...) cuyo recuerdo es un borrón para nuestra Historia». Desde la época de «la revolución de los españoles en Aranjuez (...) se cuenta la libertad española» ${ }^{80}$.

Fuera de Cádiz, y poco antes de la llegada de Fernando VII, también se vinculaba el 19 de marzo tanto a la Constitución como al Motín de Aranjuez ${ }^{81}$. Una canción publicada por el ayuntamiento de Granada dedicaba versos a ambos acontecimientos. El de 1808, «mil veces venturoso día», sigue siendo protagonizado por el pueblo. El pasaje más significativo es el siguiente, en el que se establece el paralelismo entre dos momentos fundamentales para el final del despotismo:

¡Constitución amada!

Allí jurada fuiste el mismo día

En que Godoy del solio descendía ${ }^{82}$.

Poco después, en mayo de 1814, Fernando VII volvió a España y, para regocijo de los serviles ${ }^{83}$, disolvió las Cortes convirtiendo a los liberales en unos traidores, haciéndoles compartir esa carga con sus enemigos los afrancesados. Esta dramática evolución se puede apreciar en El Conciso del Dos de Mayo de 1814, que contrasta enormemente con el número del 19 de marzo de 1814, al que nos hemos referido unas líneas arriba. Los antiguos vivas a Fernando se han convertido ahora en una enorme decepción al ver que el rey - mal aconsejado- no va a jurar la Constitución. Lo que antes eran promesas de libertad es ahora desesperación por una lucha que ha sido inútil:

«Y al cabo de seis años de sacrificios y heroicidades ha de ser todavía el pueblo español juguete de unos pocos individuos, que intentan destruir las leyes proyectadas, discutidas, aprobadas, juradas y publicadas con tantos torrentes de sangre ${ }^{84}$.

Veamos cómo evolucionó la imagen del Motín de Aranjuez desde que su héroe se quitó la máscara.

80 El Conciso, 63 (19 de marzo de 1814), p. 501.

81 En su obra sobre Jovellanos, publicada en Palma en 1812, Isidoro Antillón seguía relacionando al 19 de marzo con la revolución y el 2 de mayo con un sangriento asesinato (Isidoro AnTILlón y Marzo, Noticias Históricas de Don Gaspar Melchor de Jovellanos, Valencia, Universidad de Valencia, 1994, pp. 102-103).

82 Canción que en el anniversario del diez y nueve de marzo de este año, publica el Ayuntamiento constitucional de ésta ciudad, Granada, Oficina de D. Nicolás Moreno, 1814, p. 11.

83 La misma imprenta que había publicado en Granada la canción del aniversario, publicó poco después un: Epitafio a la Constitución política de la Monarquía española que nació en Cádiz a 19 de marzo de 1812 y falleció en su infancia a 12 de mayo de 1814, Granada, Oficina de D. Nicolás Moreno, 1814. BN R/60004(7).

84 El Conciso, 107 (2 de mayo de 1814), pp. 852-853. 


\section{La desmitificación del 19 de marzo (epílogo)}

Ni siquiera Fernando VII puso interés en conmemorar el 19 de marzo, pues se trataba de una fecha que comprometía su legitimidad. Aunque ya era demasiado tarde, Fernando intentó limpiar la imagen de sus padres, que tanto había contribuido a ensuciar $^{85}$. En esta línea, la Corte sólo celebró el aniversario del regreso del rey a España tras ser liberado por Napoleón, decretando en 1815 que se celebrase cada 24 de marzo como día de gala y salvas de artillería en toda la Monarquía ${ }^{86}$, y de besamanos en la Corte $^{87}$. Fernando VII quiso conmemorar esta fecha creando la Real Orden Americana de Isabel la Católica, un claro intento de fidelizar a las élites de sus revueltas Colonias $^{88}$.

Tampoco se olvidó el nuevo rey del Dos de Mayo, declarando su primer aniversario día de luto en la Corte y encomendando una misa a las iglesias madrileñas. Aunque la Gaceta siguió haciendo recordatorios de esta fecha, y cada año hubo algún acto benéfico (como la ayuda a los familiares de las víctimas o la dotación de diez doncellas), el ensalzamiento fernandino del Dos de Mayo no es comparable al que hicieron los liberales posteriormente ${ }^{89}$. Por supuesto, a ojos de la publicística fernandina se trataba, no de un levantamiento nacional, sino de una prueba del amor de unos vasallos a «el Rey y a la Real Familia» ${ }^{90}$.

La admisión de la dedicatoria a Fernando VII convierte a la Historia razonada de los principales sucesos de la revolución de España, de José Clemente Carnicero en una narración pseudo-oficial fernandina de los hechos ${ }^{91}$. Sin grandilocuencia, este

85 Calvo Maturana, Antonio: «Del fango de los panfletos al incienso de las exequias: la paradójica rehabilitación fernandina de María Luisa de Parma (1815-1819)», en CASTELlano CAstellano, J.L. y LóPEZGuadalupe Muñoz, M.L. (coords.): Homenaje a Antonio Domínguez Ortiz, Granada, Universidad de Granada, 2008, vol. III, pp. 183-202.

86 No parece casualidad que el regreso de Fernando VII a España, el 24 de marzo de 1814, se produjo en el sexto aniversario de la entrada del mismo rey en Madrid.

87 Esta real orden y la relacionada con el Dos de Mayo se pueden encontrar en la Gaceta de Madrid (n ${ }^{\circ} 50$, 25 de abril de 1815, pp. 429-430). Resulta interesante que el mismo número de la Gaceta recogiese el decreto de conmemoración del Dos de Mayo y que -a la vez- recordase una efeméride específicamente dedicada al monarca: el aniversario de su vuelta a España. Es posible que el decreto de celebración del regreso fernandino de Francia se improvisase en este momento para dar una alternativa monárquica a una fiesta "popular" como la del Dos de Mayo. Esto explicaría que la orden estuviese fechada el 25 de marzo de 1815, sólo un día después del primer aniversario. Era imposible fecharla antes, ya que no hubo celebración, así que esa era la máxima antigüedad que se podía dar al decreto para que no pareciese un parche. Las Gacetas de los años siguientes atestiguan la conmemoración del 24 de marzo con besamanos en la Corte y salvas de artillería.

88 Gaceta de Madrid, 36 (25 de marzo de 1815), pp. 316-317.

89 «La primera tentativa de los absolutistas consiste en torcer y recuperar la memoria del Dos de Mayo a favor del nuevo régimen hasta que lo den por imposible y abandonen el símbolo (...) La identidad liberal del mito se confirma claramente con la vuelta al poder de los constitucionalistas del Trienio» (DEMANGE, op. cit (nota 2), pp. 46-49). Los diputados del Trienio recuperaron el Dos de Mayo como una suerte de fiesta nacional. El decreto, fechado el 24 de abril de 1820, en: Gaceta de Madrid, 71 (26 de abril de 1820), p. 471.

90 Gaceta de Madrid, 50 (25 de abril de 1815), pp. 429-430.

91 Una comisión militar en 1818 y José Muñoz Maldonado en 1833 publicarían, de orden del rey, las dos historias oficiales fernandinas de la Guerra de la Independencia, si bien el primer proyecto quedó truncado por el Trienio. Véase: Calvo Maturana, Antonio: “Como si no hubiesen pasado jamás tales actos”: la gestión fernandina de la memoria histórica durante el Sexenio Absolutista (1814-1820)», en GARCíA MonERRIS, Encarna, Moreno Seco, Mónica y Marcuello Benedicto, Juan I. (eds.): Culturas políticas monárquicas en la España Liberal. Discursos, representaciones y prácticas (1808-1885) (en prensa). 
autor cuenta el asalto de la casa de Godoy, la conmoción del pueblo tras lograr «la libertad» y el singular placer» de la Corte y del reino por la noticia de la abdicación de Carlos IV en su hijo. Carnicero aparentaba dudar incluso la fecha del lance («creo que esto sucedió el día 19 y de San José» $)^{92}$. Aunque sin épica alguna, el pueblo es el protagonista de esta visión fernandina del Motín de Aranjuez.

Otros puntos de vista quitarían al 19 de marzo su aura popular. Ya en 1808, Vicente Martínez Colomer, tras un elogio al pueblo como ejecutor de la caída del «tirano de la patria», nos dejaba ver que el verdadero desencadenante de todo había sido una conspiración de la Guardia de Corps ${ }^{93}$. En 1814, Juan Antonio Llorente publicó en Francia (allí vivía exiliado por su apoyo a José I) las Memorias para la historia de la revolución de España. Sin pasión alguna contaba cómo por aquellos días «se tumultuó la plebe, dirigida por quien no era plebeya» ${ }^{94}$. La idea de una conspiración de los privilegiados apoyada en la impopularidad de Godoy se impuso en la pluma de los dos partidos despechados: el afrancesado y el liberal ${ }^{95}$.

Como es lógico, el fin de cualquier tipo de idealización de los sucesos de Aranjuez por parte de los liberales llegó con la "traición" de Fernando VII y sus persas. El cura liberal Juan Antonio Posse fue hecho preso en 1814 por un discurso constitucional que había realizado el año anterior. A buen seguro, sus posteriores palabras reflejan el sentir de muchos otros fernandinos liberales que se dieron de bruces con la cruda realidad: «¿Cómo podía imaginar yo que Fernando VII, prisionero, tan remoto en su vuelta como lo era entonces, en cuya defensa había hecho tanto sacrificio y sufrido tantas persecuciones, me había de sentenciar por seis años a un convento estrechísimo por causa de este sermón?"»» ${ }^{96}$.

Durante el Trienio Liberal, aunque el rey seguía siendo Fernando VII, este había perdido - por evidentes motivos- la admiración de todos los liberales. Entre 1820 y 1823 , el 19 de marzo volvió a ser conmemorado ${ }^{97}$, pero por ser el aniversario de la Constitución de Cádiz, sin que los textos mencionasen siquiera a Fernando, cuya "franca" marcha «por la senda constitucional» carecía de credibilidad alguna. En la Corte se celebraba este día con motivo de «los días de la Reina [María Josefa Amalia

92 CARNICERo, José Clemente: Historia razonada de los principales sucesos de la gloriosa revolución de España, Madrid, Imprenta de D.M. de Burgos, 1814, vol. I, pp. 69-72.

93 Martínez Colomer, Vicente: El filósofo en su quinta, o relación de los principales hechos acontecidos desde la caída de Godoy hasta el ataque de Valencia, Valencia, Imprenta de Salvador Faulí, 1808, pp. 7-11.

94 Llorente, Juan Antonio: Memorias para la historia de la revolución de España, París, Imprenta de M. Plassan, 1814, p. 16.

95 «El estado de las cosas apenas permitía semejante protesta en aquel día, y de positivo todos, todos sin excepción, aprobaban el resultado; porque cansados de la prepotencia del Favorito, deseaban ver el cetro en manos de Fernando» (Ibidem, p. 21).

96 Posse, Juan Antonio: Historia biográfica o Historia de la vida y hechos de Don Juan Antonio Posse escrita por él mismo, ed. de Richard Herr, Madrid, Centro de Investigaciones Sociales / Siglo XXI de España 1984, p. 160.

97 Anglona, Príncipe de: Discurso celebrando el aniversario del restablecimiento de la Constitución en el día 19 de marzo de 1822, Madrid, Imprenta de Amarita, c.1825. BN VE/660/19; Apertura de las escuelas públicas de La Coruña el día 19 de marzo de 1822, aniversario de la Constitución Política de la Monarquía Española, Coruña, Imprenta de Iguereta, 1822; y VILlaVERdE y ReY, José de: Sermón pronunciado en la Santa Iglesia Catedral de Granada el 19 de marzo de 1821 por el ciudadano... natural de Cádiz, canónigo del Sacromonte y rector de su colegio, Reimpreso en Cádiz, Imprenta de Niel hijo, 1821. BN VE/1493/5 
de Sajonia] y la publicación de la Constitución $)^{98}$. Pocos se acordaron por entonces del 19 de marzo de $1808^{99}$.

Muerto Fernando VII, una serie de autores pudo publicar sus impresiones sobre hechos que habían vivido ${ }^{100}$. Visto con perspectiva (y con resentimiento), el entusiasmo por la caída de Godoy había nublado cualquier otra reflexión ${ }^{101}$. Mesonero Romanos, que en 1808 era un niño, convirtió años más tarde al pueblo en una masa irracional guiada por la élite, mostrando cierta compasión por Godoy:

El odio, el rencor y la envidia que por tanto tiempo había excitado [Godoy], especialmente en ciertas clases elevadas de la sociedad, cundía y se derramaba por las masas del pueblo que, sin saber por qué y sin tener ningún agravio que vengar, se deshacían en improperios contra aquel magnate, únicamente porque le veían caído; y acaudilladas primero en Aranjuez por el turbulento conde de Montijo, disfrazado de $E l$ Tío Pedro, y en Madrid después por otros no menos interesados, consiguieron elevar en breves horas aquel motín cortesano y puramente de clase hasta el punto de un verdadero y formidable levantamiento nacional ${ }^{102}$.

En sus Memorias, José Palafox obviaba los «acontecimientos bien conocidos de Aranjuez» (una pena, porque los conocía de primera mano) y sin embargo ensalzaba a «aquel dos de mayo, antorcha de nuestra libertad» ${ }^{103}$. Durante el siglo XIX, aún a sabiendas de que era una fecha envuelta en la leyenda ${ }^{104}$, los intelectuales hicieron del Dos de Mayo un hito nacional ${ }^{105}$, quitando a su vez al Motín de Aranjuez todo el carácter épico y romántico que tuvo durante la Guerra de la Independencia; lo que no significa que hoy día conozcamos a la perfección el golpe de Estado fernandino, del que esperamos ocuparnos en próximos trabajos.

Hasta entonces, nos quedamos con el estudio de ese mito truncado y efímero que fue el 19 de marzo de 1808, tan influyente en su corta vida que fue vinculado al nacimiento de la Constitución de 1812. Lo que fue considerado por entonces la mecha

98 Gaceta de Madrid, 46 (21 de marzo de 1820), p. 306.

99 Existe, por ejemplo, la excepción de Wenceslao Argumosa, autor liberal que publicó un libro sobre Los Cinco días célebres de Madrid, siendo el primero el 19 de marzo de 1808 y el quinto el 9 de marzo de 1820. El episodio de Aranjuez aparece como «el primero de los grandes días de la nación», renovando los relatos de antaño protagonizados por el malvado favorito, el amado príncipe y el fidelísimo pueblo (ARGUMOSA, Wenceslao de: Los cinco días célebres de Madrid dedicados a la nación y a sus heroicos defensores, Madrid, Imprenta de Burgos, 1820, p. 6).

100 Algunos de estos manuscritos fueron publicados tras la muerte de sus respectivos autores, como los de Antonio Alcalá Galiano.

101 «Fue tal el gusto y universal contento, ya con la caída de Don Manuel Godoy y ya también con la abdicación de Carlos IV, que nadie reparó entonces en el modo con que este último e importante acto se había celebrado, y si había sido o no concluido con entera y cumplida libertad: todos lo creían así, llevados de un mismo y general deseo» (Toreno, Conde de: Historia del levantamiento, guerra y revolución de España, León, Akrón, 2008, v. 1, p. 117).

102 Mesonero Romanos, Ramón: Memorias de un setentón, Madrid, Tebas, 1975, p. 37.

103 Palafox, José de: Memorias, Zaragoza, Ayuntamiento de Zaragoza, 1994, pp. 31-51.

104 Como escribió Alcalá Galiano: «Ha sido común pintar el levantamiento del pueblo español en 1808 contra el poder francés, en defensa de la gloria e independencia de la patria y para rescatar al cautivo rey, de muy varia manera en cuanto al objeto a que se encaminaba o el fin que se proponía» (AlCALÁ GALIANO, op. cit., p. 348).

105 Demange, op. cit. (nota 2) y García CÁrcel, op. cit. (nota 2). 
que prendió el estallido de la guerra contra la tiranía, es a nuestros ojos un motín nobiliario. Aunque Godoy siguió siendo demonizado (y quedó marcado como símbolo del despotismo y de los vicios del Antiguo Régimen), la leyenda se quedó coja cuando su divino príncipe se cayó de los altares, quedando del lado de los enemigos de la libertad. Nos referimos a los altares del liberalismo que, a la postre, fue el sistema político vencedor y el que -como tal- escribió la Historia e "inventó la tradición" 106 en torno a centenarios y conmemoraciones que reforzaban la identidad nacional española.

A lo largo de este trabajo no hemos perdido de vista la imagen idealizada del Dos de Mayo, unos meses más tardía que la de Aranjuez, pero que - doscientos años después- goza de una excelente salud. Por mucho que los historiadores hayan puesto en duda tanto su peso en el estallido de la guerra como su carácter espontáneo, y a pesar de la plausible sospecha de que la mano de Murat estuvo detrás de todo, este lance sigue formando parte de la mitología nacional. La realidad histórica del hecho queda eclipsada por un mito que está estrechamente vinculado a la cultura española y al nacionalismo patrio, y que aún es rentable políticamente.

106 Hobsbawm, Eric y Ranger, Terence (eds.): La invención de la tradición, Barcelona, Crítica, 2002. Véanse también los trabajos de Pierre Nora sobre identidad y memoria. 